\title{
Produção sobre o handebol em periódicos nacionais: mapeamento e implicações para a subárea pedagógica
}

\section{RESUMO}

O objetivo do estudo foi mapear e discutir a produção acadêmica sobre $\mathrm{o}$ handebol nos diferentes campos de conhecimento da Educação Física, especialmente o da subárea pedagógica. Realizou-se uma pesquisa do tipo estado da arte, em 10 periódicos nacionais e tradicionais da área da Educação Física, no recorte temporal de janeiro de 2006 a dezembro de 2015. Os resultados indicaram que de 4.885 artigos publicados, 37 se relacionam com o handebol. Constatou-se a predominância da subárea pedagógica, seguida pela biodinâmica e pela sociocultural. Observou-se uma lacuna a partir das pesquisas analisadas, referente à abordagem do ensino do handebol em aulas de Educação Física escolar segundo as particularidades desse meio, mesmo com predomínio de estudos na subárea pedagógica.

PALAVRAS-CHAVE: Esporte; Educação física; Ensino
Mayara de Sena Cagliari

Mestrado

Universidade Estadual Paulista - UNESP

Rio Claro, São Paulo, Brasil

mayara_cagliari@hotmail.com

(- https://orcid.org/0000-0001-5893-2829

Guy Ginciene

Doutorado

Universidade Federal do Rio Grande do Sul -

UFRGS

Porto Alegre, Rio Grande do Sul, Brasil

guy.ginceine@ufrgs.br

https://orcid.org/0000-0001-9709-4223

Rafael Pombo Menezes

Doutorado

Universidade de São Paulo - USP

Ribeirão Preto, São Paulo, Brasil. rafaelpombo@usp.br

https://orcid.org/0000-0002-4842-641X

Carina da Silva Lara Sarruge

Mestre em Desenvolvimento Humano e Tecnologias

Universidade Estadual Paulista - UNESP

Rio Claro, São Paulo, Brasil. ca lara@yahoo.com.br

https://orcid.org/0000-0002-5447-3845

Fernanda Moreto Impolcetto

Doutora em Desenvolvimento Humano e Tecnologias

Universidade Estadual Paulista - UNESP

Rio Claro, São Paulo, Brasil fernanda.moreto@unesp.br https://orcid.org/0000-0003-0463-0125 


\title{
Handball's production in national journals: mapping and implications for pedagogical subárea
}

\begin{abstract}
The study's aim was mapping and discuss the academic production on handball in different fields of knowledge in Physical Education, especially on that of the pedagogical subarea. State-of-the-art research was carried out in 10 national and traditional periodicals from the Physical Education area, from January 2006 to December 2015. The results indicated from 4,885 published articles, 37 are related to handball. It was verified the predominance of the pedagogical subarea, followed by biodynamic and, sociocultural. Thus, a gap was observed from the surveys analyzed, referring to the approach of teaching handball in classes of Physical Education school according to the particularities of this field of knowledge.
\end{abstract}

KEYWORDS: Sport; Physical education; Teaching

\section{Producción sobre el balonmano en periódicos nacionales: mapeamiento e implicaciones para la subárea pedagógica}

\section{RESUMEN}

El objetivo del estudio fue mapear y discutir la producción académica sobre el balonmano en los diferentes campos de conocimiento de la Educación Física, especialmente el de la subárea pedagógica. Se realizó una investigación del tipo estado del arte, en 10 periódicos nacionales y tradicionales del área de la Educación Física, en el recorte temporal de enero de 2006 a diciembre de 2015. Los resultados indicaron que de 4.885 artículos publicados, 37 se relacionan con el balonmano. Se constató la predominancia de la subárea pedagógica, seguida por la biodinámica y la sociocultural. Se observó una laguna a partir de las investigaciones analizadas, referente al abordaje de la enseñanza del balonmano en clases de Educación Física escolar según las particularidades de ese medio, incluso con el predominio de estudios en la subárea pedagógica.

PALABRAS-CLAVE: Deporte; Educación física; Enseñanza 


\section{INTRODUÇÃO}

As pesquisas na área da Educação Física assumiram destaque em meados da década de 1970, em função da criação e implantação de programas de pós-graduação, do financiamento e fomento para trabalhos científicos, da ida de pesquisadores para o exterior, entre outras iniciativas, que impulsionaram e deram visibilidade para a área (BRACHT, 1993). A partir de então houve maior interesse, dentre outros, pela investigação da produção científica, para analisar as tendências apontadas pelos estudos de acordo com as temáticas, os aportes metodológicos e os referenciais teóricos. A necessidade de estudos desse tipo vai além do mapeamento, pois podem fomentar novas produções e delineamentos. Um dos possíveis modelos de pesquisa para diagramar a produção do conhecimento é o estudo do tipo "estado da arte".

Pesquisadores da área da Educação Física têm se debruçado na realização de pesquisas desse tipo para identificar o panorama das publicações e as possíveis lacunas existentes na área (BETTI; FERRAZ; DANTAS, 2011; RUFINO et al., 2014; ONTAÑÓN; DUPRAT; BORTOLETO, 2012; MAGRIN; SIMÕES; MOREIRA, 2014; LOPEZ; SILVEIRA; STIGGER, 2016).

A expressão "estado da arte" reflete o "estado do conhecimento", ou seja, os progressos e entraves que determinada área ou objeto de conhecimento tem apresentado em um dado período. Seu principal objetivo é o de mapear os estudos produzidos sobre determinado assunto, a fim de compreender os avanços e as barreiras que interferem no cenário científico (PICHETH, 2007).

Em especial no contexto do handebol, diferentes pesquisas vêm sendo concluídas com o intuito de tratar panoramas específicos de seus subtemas, não necessariamente utilizando-se do tipo "estado da arte", mas promovendo importantes reflexões sobre as fronteiras do conhecimento na modalidade. Há exemplo, pode-se destacar as pesquisas de Aguilar (2014), Prieto, Gomez \& Sampaio (2015), Krahenbühl et al. (2018) e Modolo et al. 2018).

Enquanto área de conhecimento, a Educação Física foi caracterizada por Manoel e Carvalho (2011), a partir das linhas de pesquisas presentes nos cursos de pós-graduação brasileira, em três grandes subáreas de conhecimento: a) biodinâmica (relacionada às disciplinas de biomecânica, fisiologia do exercício, aprendizagem e desenvolvimento motor, controle motor e alguns campos aplicados como nutrição esportiva, treinamento e rendimento físico e esportivo); b) sociocultural (com temas referentes ao esporte, práticas corporais e atividade física sob a perspectiva da sociologia, antropologia, história e filosofia); e c) pedagógica (abrange temas inerentes à formação de professores, à organização curricular, aos métodos de ensino, à pedagogia do esporte, além de aspectos metodológicos, sociais, políticos e filosóficos da educação). 
O presente artigo tem como objetivo mapear e discutir a produção acadêmica sobre o handebol nos diferentes campos de conhecimento da Educação Física, especialmente o da subárea pedagógica. Para isso, serão respondidas as seguintes questões: i) Qual será o direcionamento das pesquisas científicas produzidas com a temática do handebol no campo da Educação Física? ii) Quais as implicações dessas publicações para a subárea pedagógica?

\section{MÉTODO}

Trata-se de uma pesquisa de revisão de literatura, do tipo estado da arte, que se aproxima das revisões bibliográficas na medida em que analisa a produção científica em determinada área e fornece um panorama sobre um tema específico, evidenciando novas ideias, métodos e/ou subtemas que têm recebido maior ou menor ênfase na literatura selecionada (NORONHA; FERREIRA, 2000). Essas pesquisas são reconhecidas por se apropriarem de um método de caráter descritivo da produção acadêmica sobre o tema investigado, observando cada trabalho e o conjunto deles (FERREIRA, 2002).

Segundo Brandão, Baeta e Rocha (1986), a expressão “estado da arte” ou "estado do conhecimento" resulta de uma tradução literal do inglês e tem por objetivo realizar levantamentos do que se conhece sobre um determinado assunto em dada área de conhecimento. Assim, distinguem-se das revisões sistemáticas ao passo que não se obrigam à formulação de uma questão de investigação, ao estabelecimento de estratégias de diagnóstico crítico e na exigência de critérios de inclusão e exclusão dos estudos (DAVIES, 2007).

As pesquisas do tipo "estado da arte" direcionam os olhares de sua análise na problematização e metodologia dos estudos, sendo sua finalidade central o mapeamento da área em questão, que posteriormente servirá como uma referência para a justificada lacuna que a investigação que se pretende realizar poderá preencher (COSTA, 2010; PINHEIRO, 2012; MILANI, 2013). Algumas características para busca, seleção e análise das pesquisas do tipo "estado da arte" são assim elencadas: delimitações de períodos, escolha do tipo de documentos que serão selecionados (periódicos, artigos, dissertações, teses, etc.), leituras orientadas e criteriosas dos documentos selecionados, organização de unidades de análise dos materiais e análise final dos documentos a partir das unidades identificadas (PICHETH, 2007).

Optou-se pela busca e seleção de artigos em 10 periódicos nacionais e tradicionais da área da Educação Física (BETTI; FERRAZ; DANTAS, 2011; RUFINO; DARIDO, 2011; BRACHT et al., 2011; LOPEZ; SILVEIRA; STIGGER, 2016; KRAHENBÜHL et al., 2018), tendo como recorte temporal o período de janeiro de 2006 até dezembro de 2015. Tais periódicos foram selecionados a 
partir dos seguintes critérios: 1) que tivessem publicações na área da Educação Física escolar, verificadas por meio de seus escopos, diretrizes de publicação e histórico na área; 2) revistas que tratassem a temática da Educação Física a partir de diferentes perspectivas teóricas (excluiu-se periódicos explicitamente disciplinares); 3) manter periodicidade regular e acessibilidade online. Nesse sentido, 10 periódicos cumpriram com os critérios e fizeram parte da pesquisa, sendo de estratificação A2 até B4 (segundo Qualis Capes - 2016). Esses critérios foram definidos previamente, sem conhecimento dos artigos existentes ou das revistas selecionadas. No Quadro I estão apresentadas as principais características dos periódicos selecionados.

Quadro I. Revistas selecionadas para pesquisa.

\begin{tabular}{|c|c|c|}
\hline NOME DA REVISTA & INSTITUIÇÃO RESPONSÁVEL & QUALIS CAPES \\
\hline Revista Movimento & $\begin{array}{l}\text { Universidade Federal do Rio Grande do } \\
\qquad \text { Sul }\end{array}$ & A2 \\
\hline $\begin{array}{c}\text { Revista Brasileira de Ciências do } \\
\text { Esporte (RBCE) }\end{array}$ & $\begin{array}{c}\text { Colégio Brasileiro de Ciências do } \\
\text { Esporte }\end{array}$ & B1 \\
\hline $\begin{array}{l}\text { Revista Brasileira de Educação } \\
\text { Física e Esporte (RBEFE) }\end{array}$ & Universidade de São Paulo & B1 \\
\hline Revista da Educação Física & Universidade Estadual de Maringá & B1 \\
\hline Revista Motriz & $\begin{array}{l}\text { Universidade Estadual Paulista "Julio de } \\
\text { Mesquita Filho" }\end{array}$ & B1 \\
\hline $\begin{array}{c}\text { Revista Brasileira de Ciência e } \\
\text { Movimento (RBCM) }\end{array}$ & Universidade Católica de Brasília & B2 \\
\hline Revista Motrivivência & Universidade Federal de Santa Catarina & B2 \\
\hline $\begin{array}{l}\text { Revista Mackenzie de Educação } \\
\text { Física e Esporte (REMEFE) }\end{array}$ & Universidade Presbiteriana Mackenzie & B3 \\
\hline Revista Pensar a Prática & Universidade Federal de Goiás & B2 \\
\hline Revista Conexões & $\begin{array}{l}\text { Faculdade de Educação Física da } \\
\text { Universidade Estadual de Campinas }\end{array}$ & B4 \\
\hline
\end{tabular}

$\mathrm{O}$ acesso aos periódicos ocorreu via internet, visto que todas as publicações dos últimos 10 anos encontram-se disponíveis online. Para garantir a validade e a confiabilidade dos dados deste estudo, duas pesquisadoras selecionaram os artigos, a partir da leitura de todos os títulos dos trabalhos publicados nas respectivas revistas, sendo. Foram considerados para análise posterior, 
somente os manuscritos que apresentaram o "handebol" como assunto da pesquisa. Contudo, realizou-se a leitura do resumo e das palavras chave dos artigos que geraram dúvidas, a fim de decidir sobre a inclusão ou exclusão na amostra. Dessa forma, não foram utilizados procedimentos automáticos de busca. As mesmas autoras que fizeram as etapas anteriores, prosseguiram com a classificação dos artigos selecionados nas subáreas definidas.

Primeiramente, realizou-se a quantificação do número de artigos publicados em cada um dos periódicos, bem como os relacionados com a temática da pesquisa. Em seguida, os artigos que apresentaram a temática do "handebol" foram alocados em determinadas categorias de análise, para posterior apreciação dos conteúdos. As categorias foram selecionadas de acordo com as três principais subáreas de concentração dos programas de pós-graduação da Educação Física brasileira, de modo semelhante aos trabalhos de Manoel e Carvalho (2011), e Lopez, Silveira e Stigger (2016), sendo elas: biodinâmica, sociocultural e pedagógica. Por fim, buscou-se analisar a partir desse mapeamento, as principais implicações para a subárea pedagógica.

\section{RESULTADOS}

Após a busca foram selecionados 37 artigos que abordaram a temática do handebol em diversas áreas do conhecimento. O quadro II apresenta o número total de artigos publicados e os artigos relacionados ao handebol encontrados em cada periódico ao longo do período pesquisado.

Quadro II. Número de artigos publicados em cada um dos periódicos, bem como os relacionados com a temática da pesquisa.

\begin{tabular}{|c|c|c|c|c|c|c|c|c|c|c|c|}
\hline $\begin{array}{l}\text { Ano/ } \\
\text { Periódico }\end{array}$ & 2006 & 2007 & 2008 & 2009 & 2010 & 2011 & 2012 & 2013 & 2014 & 2015 & TOTAL \\
\hline CONEXÕES & 13 & 14 & $\begin{array}{l}79 \\
(3)\end{array}$ & 24 & 35 & $\begin{array}{l}20 \\
(1)\end{array}$ & $\begin{array}{l}47 \\
(2)\end{array}$ & 51 & $\begin{array}{l}34 \\
(1)\end{array}$ & $\begin{array}{l}60 \\
(1)\end{array}$ & $377(8)$ \\
\hline $\begin{array}{l}\text { MOTRIVIVÊ } \\
\text { NCIA }\end{array}$ & 19 & 20 & 39 & 22 & 34 & 32 & 37 & 37 & 41 & 49 & $330(0)$ \\
\hline MOTRIZ & 33 & 43 & $\begin{array}{l}55 \\
(1)\end{array}$ & 103 & $\begin{array}{l}116 \\
(2)\end{array}$ & $\begin{array}{l}82 \\
(1)\end{array}$ & 76 & 85 & $\begin{array}{l}59 \\
(1)\end{array}$ & 55 & 707 (5) \\
\hline MOVIMENTO & 27 & 28 & 30 & 38 & 62 & $\begin{array}{l}55 \\
(1)\end{array}$ & 58 & 57 & $\begin{array}{l}86 \\
(1)\end{array}$ & $\begin{array}{l}76 \\
(2)\end{array}$ & $517(4)$ \\
\hline $\begin{array}{l}\text { PENSAR A } \\
\text { PRÁTICA }\end{array}$ & 19 & 21 & 30 & 36 & $\begin{array}{l}41 \\
(1)\end{array}$ & $\begin{array}{l}46 \\
(1)\end{array}$ & 64 & 78 & 79 & 74 & $488(2)$ \\
\hline RBCM & 51 & 57 & $\begin{array}{r}50 \\
(1)\end{array}$ & 55 & 57 & 52 & 56 & $\begin{array}{l}80 \\
(1)\end{array}$ & 79 & 80 & $617(2)$ \\
\hline REMEFE & $\begin{array}{l}33 \\
(1)\end{array}$ & $\begin{array}{l}55 \\
(1)\end{array}$ & $\begin{array}{l}55 \\
(2)\end{array}$ & 33 & $\begin{array}{l}39 \\
(1)\end{array}$ & 24 & 25 & 30 & $\begin{array}{l}30 \\
(2)\end{array}$ & 0 & $324(7)$ \\
\hline $\begin{array}{l}\text { REVISTA DA } \\
\text { EF }\end{array}$ & 24 & 23 & $\begin{array}{r}60 \\
(1)\end{array}$ & 60 & 60 & 60 & 60 & 60 & $\begin{array}{l}60 \\
(1)\end{array}$ & $\begin{array}{l}60 \\
(1)\end{array}$ & $527(3)$ \\
\hline RBCE & 35 & 39 & 37 & 40 & 60 & 66 & $\begin{array}{l}52 \\
(1)\end{array}$ & 57 & $\begin{array}{c}121 \\
(1)\end{array}$ & 53 & $560(2)$ \\
\hline
\end{tabular}




$\begin{array}{|lccccccccccc|}\text { RBEFE } & 28 & 24 & 28 & 34 & 48 & 58 & 57 & 54 & 53 & 54 & 438(4) \\ \text { TOTAL } & 282 & 324 & 463 & 445 & 552 & 495 & 532 & 589 & 642 & 561 & 4885(37) \\ \text { (por ano) } & (1) & (1) & (8) & (0) & (5) & (4) & (3) & (1) & (8) & (6) & \end{array}$

Os resultados indicam que de 4.885 artigos publicados nos 10 periódicos durante o recorte temporal estabelecido, 37 se relacionam com o handebol (0,75\%). Trata-se de um esporte específico dentro do imenso rol de conteúdos e/ou áreas de estudo da Educação Física, o que pode explicar o reduzido número de estudos encontrados.

Apesar disso, observa-se que o handebol é uma modalidade muito praticada no Brasil (DIESPORTE, 2017), mas muito concentrada no ambiente escolar (SILVA et al., 2011). Dessa forma, será que as pesquisas da amostra sobre o handebol fazem referência ao ambiente escolar?

Considerando as subáreas de pesquisa na Educação Física, foi possível constatar nos achados deste estudo a predominância da pedagógica (48,64\% - 18 artigos), seguida pela biodinâmica $(45,94 \%$ - 17 artigos) e pela sociocultural (5,42\% - 2 artigos). Esses resultados destacam uma frequência maior de artigos da subárea pedagógica, contrapondo a prevalência da biodinâmica em grande parte dos estudos realizados na área da Educação Física (MANOEL; CARVALHO, 2011; IMPOLCETTO; DARIDO, 2016; BRACHT et al. 2011; LOPEZ; SILVEIRA; STIGGER, 2016).

Uma possível explicação para os achados diferentes deste artigo, diz respeito ao aumento, nos últimos anos, de estudos sobre a Pedagogia do Esporte no Brasil, em especial sobre os Jogos Esportivos Coletivos e de invasão. Grande parte das produções referentes à Pedagogia do Esporte, no entanto, diz respeito à lógica desses esportes. O voleibol, apesar de ser coletivo, possui uma lógica diferente do handebol, futsal, basquetebol, entre outros que são classificados como de invasão (GONZÁLEZ; BRACHT, 2012).

Williams e Hodges (2005) afirmam que o mundo dos esportes tem aceitado com entusiasmo a Ciência do Esporte no campo de atuação, apesar das disciplinas da biodinâmica predominarem, normalmente por serem mais consideradas e aceitas do que as outras subáreas.

A disciplina que tem o intuito de olhar para o ensino dos esportes e de outras práticas corporais, dentro da área das Ciências do Esporte é a Pedagogia do Esporte. Um dos objetivos dessa área é superar o ensino tradicional, caracterizado como aquele voltado exclusivamente para o ensino e aprendizagem das técnicas esportivas (GALATTI et al., 2014; REVERDITO; SCAGLIA; PAES, 2009; HINO; REIS; ANEZ, 2007; FORTES et al., 2012). Apesar disso, ainda são poucos os estudos voltados para a Pedagogia do Esporte e as abordagens atuais para o ensino do handebol, por exemplo, considerando o contexto escolar. 
Assim, faz-se necessária uma análise dos artigos encontrados neste processo de revisão, alocados nas três subáreas de concentração da Educação Física, focando-se nas possíveis implicações desses achados para a subárea pedagógica.

\section{Subárea pedagógica}

Como apresentado anteriormente e contrapondo a tendência apresentada por outros estudos, que relataram maior frequência da subárea biodinâmica, foi encontrada neste estudo maior número de artigos da subárea pedagógica (48,64\%). De modo geral, grande parte das pesquisas pertencentes a esta categoria dizem respeito aos processos de ensino do handebol (MENEZES; REIS, 2014; MENEZES; MORATO; REIS, 2015; REIS; CASTELLANI, 2012; CUNHA; ESTRIGA; BATISTA, 2014; MENEZES; MARQUES; NUNOMURA, 2015; RICCI et al., 2011; MENEZES; FREIRE; BOFF, 2014; MENEZES, 2011; BORGES et al., 2015; MENEZES; SOUSA; BRAGA, 2011; MENEZES; REIS; TOURINHO-FILHO, 2015; MENEZES, 2010; CASTRO; GIGLIO; MONTAGNER, 2008). Outros, porém, se dedicam a avaliar a efetividade de uma intervenção e/ou situação imposta sob um tópico particular (CLEMENTE; ROCHA, 2012; GRECO et al., 2015; CLEMENTE; ROCHA; MENDES, 2014; CANCIGLIERI; MELARI; PINHEIRO, 2008; MENEZES; REIS, 2010).

Em relação aos tipos de pesquisas empregados, especificamente para obtenção dos dados, 55,6\% dos trabalhos dessa subárea contam com a participação de treinadores e/ou jogadores (REIS; CASTELLANI, 2012; CUNHA; ESTRIGA; BATISTA, 2014; MENEZES; REIS, 2014; MENEZES; MORATO; REIS, 2015; MENEZES; MARQUES; NUNOMURA, 2015; CLEMENTE; ROCHA, 2012; CANCIGLIERI; MELARI; PINHEIRO, 2008; RICCI et al., 2011; CLEMENTE; ROCHA; MENDES, 2014; GRECO et al., 2015), enquanto 44,4\% utilizam-se da coleta documental e/ou revisão de literatura como fonte de dados da pesquisa (BORGES et al., 2015; MENEZES; SOUSA; BRAGA, 2011; CASTRO; GIGLIO; MONTAGNER, 2008; MENEZES; REIS, 2010; MENEZES, 2011; MENEZES; REIS; TOURINHO-FILHO, 2015; MENEZES, 2010; MENEZES; FREIRE; BOFF, 2014).

Por outro lado, as pesquisas que fazem uso de sujeitos utilizam-se de técnicas diversificadas para obtenção dos dados como entrevistas (CUNHA; ESTRIGA; BATISTA, 2014; MENEZES; REIS, 2014; MENEZES; MORATO; REIS, 2015; MENEZES; MARQUES; NUNOMURA, 2015), questionários (REIS; CASTELLANI, 2012; CANCIGLIERI; MELARI; PINHEIRO, 2008), observação (CLEMENTE; ROCHA, 2012; CANCIGLIERI; MELARI; PINHEIRO, 2008) e/ou implementação (CLEMENTE; ROCHA, 2012; GRECO et al., 2015; RICCI et al., 2011; 
CLEMENTE; ROCHA; MENDES, 2014). Os sujeitos variam desde treinadores de equipes ou docentes da disciplina de handebol no ensino superior (REIS; CASTELLANI, 2012; CUNHA; ESTRIGA; BATISTA, 2014; MENEZES; REIS, 2014; MENEZES; MORATO; REIS, 2015; MENEZES; MARQUES; NUNOMURA, 2015) até escolares com ou sem experiência no esporte (CLEMENTE; ROCHA, 2012; CANCIGLIERI; MELARI; PINHEIRO, 2008; RICCI et al., 2011; CLEMENTE; ROCHA; MENDES, 2014; GRECO et al., 2015).

\section{Subárea biodinâmica}

A subárea da biodinâmica representa 45,94\% das pesquisas encontradas neste estudo, e ocupa uma posição hegemônica na Educação Física, haja vista a sua representatividade dentro da pós-graduação brasileira. Uma pesquisa publicada em 2010 indicava que 12 programas de pósgraduação têm a biodinâmica como subárea predominante, o que corresponde a $57 \%$ do total. Também, dos 860 projetos de pesquisa cadastrados em todos os programas na época da pesquisa, 67,4\% eram da subárea biodinâmica (MANOEL; CARVALHO, 2011).

Os principais temas desenvolvidos pelas pesquisas dessa subárea são: treinamento esportivo (29.41\%), fisiologia (23,53\%), cineantropometria (23,53\%), biomecânica (11,76\%) e aprendizagem motora $(11,76 \%)$. Pontualmente, elas objetivam a melhora das capacidades físicas, técnicas ou táticas dos praticantes e/ou do próprio esporte. Para isso, 88,23\% dos artigos encontrados nessa subárea faz uso de atletas de handebol (PIRES; FLORES; BRANDÃO, 2008; TELES; VOLOSSOVITCH, 2015; VASQUES et al., 2008a; VASQUES et al., 2008b; NOGUEIRA; DEL VECCHIO, 2008; HESPANHOL-JUNIOR et al., 2012; ALVARENGA et al., 2014; MARCHETTI et al., 2014), técnicos (MASSUÇA; FRAGOSO, 2010; COSTA; MASSA, 2006; UEZO et al., 2008), deficientes físicos (OLIVEIRA; van MUSTER, 2013) e/ou escolares praticantes de handebol (CLEMENTE et al., 2014; SANTOS et al., 2014; DELLAGRANA et al., 2010), como sujeitos da pesquisa.

Também, os estudos são desenvolvidos a partir de revisões de literatura (ALVES; BARBOSA; PELLEGRINOTTI, 2008; FERREIRA, 2010), intervenção (treino, tarefa ou teste) (CLEMENTE et al., 2014; NOGUEIRA; DEL VECCHIO, 2008; VASQUES et al., 2008a; VASQUES et al., 2008b; SANTOS et al., 2014; DELLAGRANA et al., 2010; MARCHETTI et al., 2014; OLIVEIRA; van MUSTER, 2013; ALVARENGA et al., 2014), questionário (PIRES; FLORES; BRANDÃO, 2008), entrevista (MASSUÇA; FRAGOSO, 2010; COSTA; MASSA, 2006; UEZO et al., 2008) e/ou análise de jogo (TELES; VOLOSSOVITCH, 2015; HESPANHOLJUNIOR et al., 2012). 
A preeminência da subárea biodinâmica dentro da Educação Física está intimamente ligada a vestígios históricos, visto que durante muito tempo esta atrelava-se às ciências naturais, orientada por disciplinas como fisiologia, biomecânica, treinamento físico, aprendizagem motora, entre outras. Logo, as pesquisas relacionadas ao handebol também transitam nesse universo, segundo os achados deste estudo, quando é concebido em um contexto de esporte profissional, que é apenas uma das possibilidades de envolvimento com a sua prática.

\section{Subárea sociocultural}

Representando 5,42\%, duas das pesquisas sobre handebol que compõe a amostra, encontram-se a subárea sociocultural. Sua linha de investigação é pautada nas ciências humanas e sociais, o que demonstra a estreita relação da Educação Física com a área da educação, sociologia, filosofia e história (MANOEL; CARVALHO, 2011).

As pesquisas dessa subárea objetivaram verificar o nível de adesão à prática do handebol nas aulas de Educação Física e no lazer (SILVA et al., 2011), assim como analisar o ambiente em que atletas talentosos de handebol foram desenvolvidos em comparação a preceitos elucidados por diferentes autores (MENDONÇA et al., 2007). Ambas utilizaram-se de sujeitos - estudantes ou atletas de alto rendimento e obtiveram dados por meio da aplicação de questionário e entrevista, respectivamente.

\section{DISCUSSÃO}

A partir do mapeamento das pesquisas científicas produzidas com a temática do handebol, tornou-se possível visualizar algumas tendências e enfoques. Constatou-se a predominância da subárea pedagógica em detrimento da biodinâmica (embora com a diferença de um artigo entre essas) e sociocultural (com apenas dois artigos). Esses resultados contradizem em parte o exposto na literatura por outras revisões realizadas na área da Educação Física, as quais carecem de publicações relacionadas às subáreas sociocultural e pedagógica (LOPEZ; SILVEIRA; STIGGER, 2016; IMPOLCETTO, 2016). Nesta pesquisa apenas a subárea sociocultural apresentou número muito reduzido de estudos.

Analisando outras pesquisas que investigaram as publicações científicas sobre handebol (AGUILAR, 2014; PASKO; MIRANDA; RESENDE, 2006; PIETRO; GÓMEZ; SAMPAIO, 2015), observa-se que a maior parte dos artigos encontrados possui características da subárea biodinâmica. O Quadro III ilustra esses resultados. 
Quadro III: Revisões analisadas e alocadas nas três subáreas da Educação Física.

\begin{tabular}{|c|c|c|c|c|}
\hline Autor/Ano & Amostra & $\begin{array}{c}\text { Subárea } \\
\text { predominante }\end{array}$ & $\begin{array}{l}\text { Segunda } \\
\text { subárea }\end{array}$ & $\begin{array}{c}\text { Subárea menos } \\
\text { predominante }\end{array}$ \\
\hline Aguilar (2014) & Web of Science & Biodinâmica & Pedagógica & Sociocultural \\
\hline $\begin{array}{l}\text { Pasko, Miranda e } \\
\text { Resende (2006) }\end{array}$ & $\begin{array}{l}\text { NUTESES e } \\
\text { CAPES }\end{array}$ & Biodinâmica & Pedagógica & Sociocultural \\
\hline $\begin{array}{l}\text { Pietro, Gómez e } \\
\text { Sampaio (2015) }\end{array}$ & $\begin{array}{l}\text { Web of Science e } \\
\text { MEDLINE }\end{array}$ & Biodinâmica & Pedagógica & Sociocultural \\
\hline Presente artigo & $\begin{array}{l}10 \text { revistas } \\
\text { tradicionais na } \\
\text { área da } \mathrm{EF}\end{array}$ & Pedagógica & Biodinâmica & Sociocultural \\
\hline
\end{tabular}

Os dados evidenciam o predomínio da subárea biodinâmica nas outras pesquisas de revisão sobre handebol. Um dos possíveis motivos para essa divergência se deve à fase de levantamento de dados. No caso da presente pesquisa, a amostra localizou-se em revistas brasileiras com escopo voltado à produção do conhecimento na área da Educação Física e afins, que compreendem abordagens socioculturais, filosóficas e pedagógicas, sendo portanto, os principais locais de publicação para a subárea pedagógica nacional. A biodinâmica na Educação Física brasileira parece concentrar suas publicações em periódicos internacionais, ao contrário da pedagógica, que possui como principais revistas as selecionadas na amostra. Além disso, em muitos casos o contexto das pesquisas da subárea pedagógica representa particularidades da Educação Física brasileira, algo não tão vislumbrado para publicação em revistas do exterior.

Considerando o objetivo dessa pesquisa, a subárea pedagógica foi escolhida para ser analisada e discutida de maneira mais aprofundada. Primeiramente, é importante ressaltar que o levantamento de dados do conteúdo handebol dentro da subárea pedagógica, poderia supor forte correlação com a Educação Física escolar, haja vista que esse é um dos ambientes no qual desenvolve-se o processo de ensino e aprendizagem desse esporte. Contudo, nenhum artigo da amostra refere-se ao ensino e aprendizagem do handebol na escola, demonstrando certa desvalorização e/ou desinteresse por parte dos pesquisadores, que debruçam os olhares para o handebol sob outros enfoques.

No mesmo sentido, o estudo de Antunes et al. (2005) evidenciou a escassa produção acadêmica na área da Educação Física escolar. Para constatar o baixo número de estudos e pesquisas, os autores realizaram uma análise de 11 periódicos científicos nacionais e internacionais que publicam artigos da área pedagógica entre os anos de 1999 a 2003 e como resultados encontraram que dos 1139 artigos encontrados, 21,2\% se referiam a Educação Física escolar. Concluíram assim, que o contexto escolar não é objeto privilegiado de estudo para a Educação Física e quando o é, o processo de ensino e aprendizagem que deveria ser o alvo principal das 
pesquisas, não é tema prioritário de investigação. Eles ainda salientam que uma mudança nesta conjuntura perpassa necessariamente pela transformação do status da área pedagógica dentro da Educação Física (ANTUNES et al., 2005). Ao diferenciarem os artigos encontrados sobre Educação Física escolar em quatro categorias distintas (fundamentação, intervenção, diagnóstico, e outros), Bracht et al. (2011) concluíram que o total de artigos encontrados nos trinta anos investigados, não são compatíveis com a importância que a subárea pedagógica possui com relação ao campo da Educação Física de maneira geral, seguindo uma tendência de desvalorização encontrada não só nacionalmente, como também em nível internacional.

Outro fator importante a ser considerado nessas pesquisas, diz respeito à participação de escolares nos estudos, porém, sem vínculos com aspectos ligados à educação escolar. Esse fenômeno tem sido bastante comum, haja vista a facilidade em se ter um grande número de participantes, nivelados por idade e/ou características, em um mesmo ambiente para coleta de dados (BETTI, 2001). Também é comum a ocorrência de pesquisas com escolares participantes de atividades extracurriculares, ou seja, no período contrário às aulas regulares onde acontecem atividades esportivas, nas quais os participantes são os próprios alunos da escola, mas em um contexto diferente da disciplina de Educação Física.

Contudo, observa-se que algumas pesquisas da subárea pedagógica trazem dados que podem ser relacionados com a Educação Física escolar e oferecerem contribuições significativas para o processo de ensino e aprendizagem do handebol na escola. Por exemplo, em um dos artigos dessa amostra, Menezes, Sousa e Braga (2011) buscaram apresentar os problemas da iniciação ao handebol considerando diferentes perspectivas, principalmente às relacionadas com as metodologias de ensino dos Jogos Coletivos Esportivizados (JCE's) que podem ser aplicadas à categoria mirim (sub-12). Para isso, partiram de uma reflexão crítica sobre a iniciação esportiva, do jogo e das características dessa categoria e finalizaram discutindo as possibilidades e metodologias de ensino positivas para o handebol na categoria em questão. Dentre as conclusões estabelecidas pelos autores, entende-se que duas delas podem oferecer contribuições para o ensino do handebol na Educação Física escolar. A primeira diz respeito ao enfoque de que na categoria mirim (12 anos) é importante buscar o aprendizado que permita identificar alterações importantes em 37 relação ao cenário do jogo, ou seja, sair do modo de aglutinação em torno da bola e grande verbalização dos jogadores, e transpor para um cenário "descentralizado" no jogo de handebol. Esse tipo de cenário, no qual os alunos se organizam em torno da bola é muito recorrente nas aulas de Educação Física, pois observam a bola como objeto mais importante. Assim, o professor de Educação Física que trabalha com alunos desta faixa etária (em torno do $6^{\circ}$ e $7^{\circ}$ ano do Ensino Fundamental) pode se beneficiar desse conhecimento e desenvolver um plano de ensino voltado a essa mudança de 
cenário, de modo que pouco a pouco os alunos façam do handebol um jogo descentralizado e compreendam o porquê disso. A segunda contribuição está relacionada às metodologias adotadas para o ensino do handebol, que podem prontamente serem utilizadas pelos professores na escola. Os autores enfatizam a necessidade de variabilidade das situações de jogo para essa faixa etária, tais como desigualdades numéricas (como o 4X3, 6X5 ou 10X9, por exemplo), mudanças de espaço da quadra e diferentes tipos de tarefas motoras. Também, ressalvam a utilização de modelos de ensino que se apropriem do jogo como ferramenta pedagógica. O jogo é um elemento importante da cultura infantil, o qual acentua a ludicidade, cooperação e ao mesmo tempo a competição. Nele, permite-se perpetrar adaptações importantes que potencializam o processo de ensino e aprendizagem, tais como restrição ou aumento do espaço físico, materiais utilizados, regras, participação de um grande número de alunos, entre outras (PAES, 2001). Assim, o ponto importante para o ensino do handebol na escola seria a utilização de jogos, com as inúmeras modificações possíveis. Compete ao professor, a partir do conhecimento da sua turma, verificar as necessidades e anseios pertinentes à sua realidade, bem como os objetivos que pretende alcançar mediante a aprendizagem.

Embora seja possível extrair de algumas pesquisas contribuições pertinentes para o ensino do handebol no contexto escolar, como feito acima, reforça-se a lacuna existente na literatura quanto ao desenvolvimento de pesquisas que realmente objetivem investigar a temática.. As mesmas necessitam atentar-se às características próprias da Educação Física escolar e a partir daí pensar em estratégias para o processo de ensino e aprendizagem do handebol nesse cenário. Desse contexto, destacam-se as seguintes características:

- disciplina obrigatória da Educação Básica, logo os alunos não optam por estarem ou não naquela aula, por aprenderem ou não o handebol;

- turmas mistas e a presença (em alguns casos) de alunos com e sem deficiência na mesma aula, participando das mesmas atividades;

- $\quad$ média de duas aulas semanais;

- o objetivo da disciplina não está voltado ao esporte de rendimento e sim à educação, buscando alcançar finalidades relacionadas à sua incorporação na vida dos alunos para que possam usufruir dessa com diversas finalidades como manutenção da saúde, lazer, apreciação crítica, etc.;

- $\quad$ curto tempo ao longo do ano para tematizar cada um dos conteúdos, prezando pela diversificação ao invés da especialização;

- necessidade de trabalhar com os conteúdos para além do saber fazer, ampliando os conhecimentos dos alunos sobre os mesmos e refletindo a respeito de valores e atitudes. 
Portanto, ressalta-se a necessidade e a importância de pesquisas que tratem da temática do handebol e, ao mesmo tempo, considerem o contexto descrito anteriormente para que contribuam cada vez mais para o processo de ensino e aprendizagem desse conteúdo na Educação Física escolar.

\section{CONSIDERAÇÕES FINAIS}

Os resultados deste estudo demonstram superioridade de publicações sobre handebol concentradas na subárea pedagógica, em detrimento da biodinâmica e sociocultural. Alguns motivos podem ser utilizados para justificar esses resultados, como o escopo dos periódicos selecionados e o crescimento da área de Pedagogia do Esporte no Brasil, especialmente com estudos voltados para os JCE e de invasão.

Pontualmente, nenhum dos trabalhos dessa subárea é próprio da Educação Física escolar e/ou se debruça a analisar os componentes desse contexto, levando em consideração suas características específicas. Com isso, observa-se uma lacuna a partir das pesquisas analisadas, referente à abordagem do ensino do handebol em aulas de Educação Física escolar segundo as particularidades desse meio. +

A classificação dos artigos de acordo com as três principais subáreas de concentração dos programas de pós-graduação da Educação Física brasileira (MANOEL; CARVALHO, 2011) mostrou-se como uma alternativa possível. Entretanto, se reconhece que dentre os periódicos que compuseram a amostra, os de estrato B3 e B4 são pouco procurados pelos docentes e discentes da pós-graduação para publicação das pesquisas das subáreas pedagógica e biodinâmica, o que pode supor a possibilidade de viés nos resultados. Fato que se mostra como uma limitação do estudo, mas não o inviabiliza.

Destaca-se também que as pesquisas da amostra não discutem os conceitos, fatos, história e/ou os valores provenientes do handebol, restringindo-se aos saberes procedimentais. Trata-se de um fenômeno recorrente na literatura esportiva, conforme apontam Barroso e Darido (2009) ao analisarem propostas da Pedagogia do Esporte. Os autores notaram um direcionamento das pesquisas para a dimensão procedimental, a qual enfatiza "o que" o aluno deve aprender a fazer. Embora o esporte não seja educativo a priori, considera-se necessário fazer dele um meio educacional, criando ambientes de aprendizagem que permitam aos alunos refletirem questões referentes aos conceitos e atitudes, como valores culturais, morais e sociais (SCAGLIA, 2014). Esse é um dos pontos no qual a literatura sobre o handebol, pertinente à subárea pedagógica, carece de publicações e abre portas para novos desdobramentos, considerando as reais necessidades e a 
importância do ensino desse esporte de forma ampliada, que favoreça uma formação integral dos alunos.

Ressalta-se, portanto, a relevância de pesquisas que tratem da temática do handebol e ao mesmo tempo olhem para as variáveis específicas do ambiente escolar - como, por exemplo, as dimensões dos conteúdos e a utilização de modelos de ensino atuais da Pedagogia do Esporte - de modo a contribuir cada vez mais para o processo de ensino e aprendizagem desse esporte.

\section{REFERÊNCIAS}

AGUILAR, Óscar Gutiérrez. Analysis of scientific prodution in handball in journals of web science. Revista de Ciencias del Deporte, v.10,n.2, p.77-88, 2014.

ALVARENGA, Caroline. Rodrigues.; HAZIME, Fuad Ahmad; COSTA, Carlos Augusto Alves; SILVA, Cristiano Sales; SILVA, Baldomero Antonio Kato; CARDOSO, Vinícius Saura. Relação entre força dos músculos rotadores do ombro e capacidade ativação do músculo transverso abdominal em atletas de handebol. Revista Brasileira de Ciência do Esporte, v. 36, n. 3, p. 679$684,2014$.

ALVES, Thiago Candido; BARBOSA, Luis Fabiano; PELLIGRINOTTI, Idico Luiz. Características fisiológicas do handebol. Revista da Faculdade de Educação Física da UNICAMP, Campinas, v. 6, ed. Especial, p. 59-71, jul. 2008.

ANDRÉ, Marli Eliza Dalmazo Afonso. Formação de professores no Brasil (1990-1998). Brasília: MEC/Inep/Comped, 2002.

ANGELUCCI, C. B.; KALMUS, J.; PAPARELLI, R.; PATTO, M. H. S. O estado da arte da pesquisa sobre o fracasso escolar (1991-2002): um estudo introdutório. Educação e Pesquisa, São Paulo, vol. 30, n. 1, p.51-72. Jan/abri, 2004.

ANTUNES, Fabia Helena Chiorboli; DANTAS, Luiz Eduardo Pinto Bastos Tourinho; BIGOTTI, Stefano; TOKUYOCHI, Jorge Hideo; TANI, Go; BRASIL, Fernanda Kundrat; ANDRÉ, Mauro. Um retrato da pesquisa brasileira em Educação Física escolar: 1999-2003. Motriz, Rio Claro, v.11 n.3 p.179-184, set./dez. 2005.

LOPEZ, Luiza Azevedo; SILVEIRA, Raquel; STIGGER, Marco Paulo. O campo da Educação Física visto a partir da produção acadêmica sobre o voleibol. Revista Brasileira de Ciência do Esporte, v. 38, n. 3, p. 235-242, 2016.

BARROSO, André Luís Ruggiero; DARIDO, Suraya Cristina. A pedagogia do esporte e as dimensões dos conteúdos: conceitual, procedimental e atitudinal. Revista da Educação Física/UEM Maringá, v. 20, n. 2, p. 281-289, 2. trim. 2009.

BETTI, Mauro; FERRAZ, Osvaldo Luiz; DANTAS, Luiz Eduardo Pinto Basto Tourinho. Educação física escolar: estado da arte e direções futuras. Revista Brasileira de Educação Física e Esporte, São Paulo, v. 25, p. 105-115, dez. 2011.

BETTI, Mauro. Mídias: aliadas ou inimigas da educação física escolar. Motriz, São 
Paulo, v.7, n.2, p.125-129, jul./dez. 2001.

BORGES, Mariane; SILVA, Anselmo Athayde Costa; FARIA, Fernando Rosch; GODOY, Priscila Samora; CALEGARI, Décio Roberto; ARAÚJO, Paulo Ferreira; GORLA, José Irineu. Handebol em cadeiras de rodas: fundamentos da modalidade. Revista da Faculdade de Educação Física da UNICAMP, Campinas, v. 13, n. 3, p. 195-212, jul./set. 2015.

BRACHT, Valter. Educação Física/Ciências do esporte: que Ciência é Essa? Revista Brasileira de Ciências do Esporte, Campinas, v. 14, n. 3, p. 111- 118. 1993.

BRACHT, Valter. et al. Educação Física Escolar como tema da produção de conhecimento nos periódicos da área no Brasil (1980-2010): parte I. Movimento, Porto Alegre, v. 17, n. 02, p. 11-34, abr./jun. 2011.

BRANDÃO, Z.; BAETA, A. M. B.; ROCHA, A. D. C. Evasão e repetência no Brasil: a escola em questão. 2. ed. Rio de Janeiro: Dois Pontos, 1986.

BRASIL. Ministério da Educação e do Desporto. Parâmetros Curriculares Nacionais: Educação Física, Terceiro e Quarto Ciclos / Secretaria de Educação Fundamental. Brasília: MEC/SEF, 1998.

BRASIL. Ministério da Educação. Base Nacional Curricular Comum (BNCC). Disponível em: http://basenacionalcomum.mec. gov.br/documentos/bncc-2versao. revista.pdf. Acesso em:

20/01/2017.

CANCIGLIERI, Paulo Henrique; MELARI, Leila Felicio; PINHEIRO, Priscila Ubiali. Handebol: Processo pedagógico e especialização precoce. Revista Mackenzie de Educação Física e Esporte, São Paulo, v. 7, n. 3, p. 79-82, 2008.

CASTRO, Jefferson Alexandre; GIGLIO, Sérgio Settani; MONTAGNER, Paulo Cesar. O jogo no ensino do handebol: proposta de um plano de ensino pensado para a prática diária. Motriz, Rio Claro, v. 14, n. 1, p. 67- 73, jan./mar. 2008.

CLEMENTE, Filipe Manuel; ROCHA, Rúben Filipe. Utilização dos jogos reduzidos no ensino do handebol: a influência nas ações táticas. Conexões: Revista da Faculdade de Educação Física da UNICAMP, Campinas, v. 10, n. 2, p. 66-76, maio/ago. 2012.

CLEMENTE, Filipe Manuel; ROCHA, Rúben Filipe; MENDES, Rui Sousa. Estudo da quantidade de jogadores em jogos reduzidos de handebol: mudança na dinâmica técnica e tática. Revista Brasileira de Educação Física e Esporte, São Paulo, v. 28, n. 1, p. 135-45, jan./mar. 2014.

CLEMENTE, Filipe Manuel; ROCHA, Rúben Filipe; MIRANDA, António; MENDES, Rui Sousa. Jogos reduzidos no handebol: Efeitos na percepção subjetiva de esforço. Revista Mackenzie de Educação Física e Esporte, São Paulo, v. 13, n. 2, p. 53-64, jul./dez. 2014.

COSTA, Juliana Miranda; MASSA, Marcelo. O processo de detecção e seleção de talentos no handebol. Revista Mackenzie de Educação Física e Esporte, v. 5, n. 2, p. 85-93. 2006.

COSTA, Sirley Terezinha Golemba. O imaginário do professor sobre o uso das tecnologias educativas: pressupostos para uma proposta de formação. 2010. 255 f. Dissertação (Mestrado 
em Educação) - Pontifícia Universidade Católica do Paraná, Curitiba, 2010 Disponível em: http://www.biblioteca.pucpr.br/tede/tde_busca/arquivo. php?codArquivo=1774. Acesso em: 9 jun. 2017.

CUNHA, Ana Filipa Vasquez Paulo; ESTRIGA, Maria Luísa Dias; BATISTA, Paula Maria Fazendeiro; Fontes do conhecimento percebidas pelos treinadores: estudo com treinadores de handebol da $1^{\text {a }}$ divisão de seniores masculinos de Portugal. Revista Movimento, Porto Alegre, v. 20, n. 3, p. 917-940, jul./set. 2014.

DAVIES, P. Revisões sistemáticas e a Campbell Collaboration. In: THOMAS, G. et al. Educação baseada em evidências: atualização dos achados científicos para a qualificação da prática pedagógica. Porto Alegre: Artmed, 2007. p. 31-43.

DELLAGRANA, Rodolfo André; SILVA, Michael Pereira; SMORALEK, André de Camargo; BOZZA, Rodrigo; NETO, Antonio Stabelini; CAMPOS, Wagner. Composição Corporal, maturação sexual e desempenho motor de jovens praticantes de handebol. Motriz, Rio Claro, v.16 n.4 p.880-888, out./dez. 2010.

FERREIRA, Norma Sandra De Almeida. As pesquisas denominadas "estado da arte". Educação \& Sociedade, Campinas, v. 23, n. 79, p. 257-272, abr. 2002.

FERREIRA, Rodrigo D'Alonso. Demandas Fisiológicas do handebol. Revista Mackenzie de Educação Física e Esporte, São Paulo, v. 9, n. 2, p. 73-82, 2010.

FORTES, Milena de Oliveira; AZEVEDO, Mario Renato; KREMER, Marina Marques; HALLA, Pedro Curi. A educação física escolar na cidade de Pelotas-RS: contexto das aulas e conteúdos. Revista da Educação Física/UEM, v. 23, n. 1, 1. trim. 2012, p. 69-78, 2012.

GALATTI, Larissa Rafaela; REVERDITO, Riller Silva; SCAGLIA, Alcides José; PAES, Roberto Rodrigues; SEOANE, Antonio Montero. Pedagogia do Esporte: tensão na ciência e o ensino dos jogos esportivos coletivos. Revista da Educação Física/UEM, v.25, p. 01-40, 2014.

GONZALÉS, Fernando Jaime; BRACHT, Valter. Metodologia do ensino dos esportes coletivos. Vitória:UFES, Núcleo de Educação Aberta e a Distância, 2012.

GREGO, Pablo Juan; MORALES, Juan Carlos Perez; ABURACHID, Layla Maria Campos; SILVA, Schelyne Ribas. Evidência de validade do teste de conhecimento tático processual para orientação esportiva - TCTP:OE. Revista Brasileira de Educação Física e Esporte, São Paulo, v. 29, n. 2, p. 313-24, abr./jun. 2015.

HAAG, Hebert. Theoretical Foundation of Sport Science as a Scientific Discipline. Schorndorf: Hofmann, SportStudies, n.6, ICSSPE, 1994.

HINO, Adriano Akira Ferreira; REIS, Rodrigo Siqueira; ANEZ, Ciro Romélio Rodriguez. Observação dos níveis de atividade física, contexto das aulas e comportamento do professor em aulas de educação física do ensino médio da rede pública. Revista Brasileira de atividade física \& saúde, Londrina, v. 12, n. 3, p. 21-30, set./dez. 2007.

IMPOLCETTO, Fernanda Moreto; DARIDO, Suraya Cristina. O "Estado da Arte" do voleibol e do voleibol na escola. Revista Brasileira de Ciência e Movimento. Brasília, v. 24, n. 4, 2016. 
JUNIOR HESPANHOL, Luiz Carlos; GIROTTO, Natalia; ALENCAR, Tiago Novato; LOPES, Alexandre Dias. Principais gestos esportivos executados por jogadores de handebol. Revista Brasileira de Ciência do Esporte, Florianópolis, v. 34, n. 3, p. 727-739, jul/set. 2012.

KRAHENBÜHL, Tathyane; et al. Produção científica sobre o ensino do handebol na educação física escolar. Corpoconsciência, v.22, n.3, p.74-85, 2018.

MACHADO, Gisele Viola; GALATTI, Larissa Rafaela; PAES, Roberto Rodrigues. Seleção de conteúdos e procedimentos pedagógicos para o ensino do esporte em projetos sociais: reflexões a partir dos jogos esportivos coletivos. Motrivivência, n. 39, p. 164-176, dez. 2012.

MAÇUSSA, Luís; FRAGOSO, Isabel. Do talento ao alto rendimento: Indicadores de acesso à excelência no handebol. Revista Brasileira de Educação Física e Esporte, São Paulo, v. 24, n. 4, p. 483- 91, out./dez. 2010.

MANOEL, Edson de Jesus; CARVALHO, Yara Maria. de. Pós-graduação na educação física brasileira: a atração (fatal) para a biodinâmica. Educação e Pesquisa, São Paulo, v. 37, n. 2, p. 389406, mai./ago. 2011.

MARCHETTI, Paulo Henrique; ORSELLI, Maria Isabel V.; MARTINS, Lúcio M. S.; DUARTE, Marcos. Effects of a full season on stabilometric Parameters of team handball elite athletes. Motriz, Rio Claro, v. 20, n. 1, p. 71-77, jan./mar. 2014.

MAGRIN, Natalia Papacídero; SIMÕES, Regina Maria Rovigati; MOREIRA, Wagner Wey. Formação profissional em educação física: estado da arte $^{1}$. Revista Kinesis , v. 2,n.32,p. 117-128, 2014.

MAZZOTTI, A. J. A. A revisão da bibliografia em teses e dissertações: meus tipos inesquecíveis - o retorno. In: BIANCHETTI, L.; MACHADO, A. M. N. (organizadores). A bússola do escrever: desafios e estratégias na orientação de teses e dissertações. São Paulo: Cortez, 2002.

MENDONÇA, Marcela Teixeira; HONDA, Rogério; MASSA, Marcelo; UEZU, Rudney. Formação e desenvolvimento de talentos esportivos no handebol masculino. Revista Mackenzie de Educação Física e Esporte, v. 6, n. 1, p. 125-135, 2007.

MENEZES, Rafael Pombo. Das situações de jogo ao ensino das fixações no handebol. Motriz, Rio Claro, v.17 n.1, p. 39-47, jan./mar. 2011.

MENEZES, Rafael Pombo. O ensino dos sistemas defensivos do handebol: considerações metodológicas acerca da categoria cadete. Revista Pensar a prática, v. 13, n. 1, p. 1-15, jan./abr. 2010 .

MENEZES, Rafael Pombo; FREIRE, Vitor Daronco; BOFF, Leonardo Cordeiro. Possibilidades Pedagógicas: 3:3 handebol mediante o jogo do pivô. Revista da Faculdade de Educação Física da UNICAMP, Campinas, v. 12, n. 4, p. 69-90, out./dez. 2014.

MENEZES, Rafael Pombo; MARQUES, Renato Francisco Rodrigues; NUNOMOURA, Myrian. O ensino do handebol na categoria infantil a partir dos discursos de treinadores experientes. Revista 
Movimento, Porto Alegre, v. 21, n. 2, p. 463-477, abr./jun. 2015.

MENEZES, Rafael Pombo; MORATO, Márcio Pereira; REIS, Heloisa Helena Baldy. Análise do jogo de handebol na perspectiva de treinadores experientes: categorias de análise ofensivas. Revista de Educação Física/UEM, Maringá, v. 26, n. 1, p. 11-20, 1 trim. 2015.

MENEZES, Rafael Pombo; REIS, Heloisa Helena Baldy. Relação entre eficácia defensiva e elementos técnico-táticos do handebol a partir dos discursos de treinadores experientes. Revista de Educação Física/UEM, Maringá, v. 25, n. 4, p. 513-526, 4 trim. 2014.

MENEZES, Rafael Pombo; REIS, Heloisa Helena Baldy. Análise do jogo de handebol como ferramenta para sua compreensão técnico-tática. Motriz, Rio Claro, v.16 n.2 p.458-467, abr./jun. 2010.

MENEZES, Rafael Pombo; REIS, Heloisa Helena Baldy; FILHO, Hugo Tourinho. Ensino aprendizagem - treinamento dos elementos técnico-táticos defensivos individuais do handebol nas categorias infantil, cadete, juvenil. Revista Movimento, Porto Alegre, v. 21, n. 1, p. 261-173, jan./mar. 2015.

MENEZES, Rafael Pombo; SOUSA, Maria Suélia dos Santos; BRAGA, José Werley Carvalho. Processo de ensino-aprendizagem-treinamento de handebol para categorias mirim em instituições não formais de ensino: concepções metodologias. Revista da Faculdade de Educação Física da UNICAMP, Campinas, v. 9, n. 2, p. 49-69, maio/ago. 2011.

MILANI, M. L. C. A presença das tecnologias educacionais no currículo dos cursos de licenciatura em matemática. 2013. 114 f. Dissertação (Mestrado em Educação) — Pontifícia Universidade Católica do Paraná, Curitiba, 2013. Disponível em:

http://www.biblioteca.pucpr.br/tede/tde_busca/arquivo. php?codArquivo=2594. Acesso em: 5 dez. 2017.

MINISTÉRIO DO ESPORTE. Diagnóstico Nacional do Esporte - Caderno I, 2015. Disponível em: http://www.esporte.gov.br/diesporte/. Acesso em 29 de novembro de 2016.

MODOLO, Felipe; BELTRAMINI, Lucia; MENEZES, Rafael Pombo. Revisão sistemática sobre o processo de ensino e de análise do goleiro de handebol. Cuadernos de Psicología del Deporte, 18(3), 234-251, 2018.

NOGUEIRA, Maurício Quian; VECCHIO, Fabrício Boscolo Del. Efeitos de treino de flexibilidade e força funcional na precisão em teste de handebol. Revista da Faculdade de Educação Física da UNICAMP, Campinas, v. 6, ed. Especial, p. 111, jul. 2008.

NORONHA, D. P.; FERREIRA, S. M. S. P. Revisões de literatura. In: Bernadete Santos Campello; Beatriz Valadares Cendón; Jeannete Marguerite Kremer. (Org.). Fontes de informação para pesquisadores e profissionais. Belo Horizonte, MG: UFMF, 2000.

OLIVEIRA, Ana Carolina Santana; MUNSTER, Mey de Abreu van; Análise da evolução de habilidades motoras relacionadas aos fundamentos do Handebol em Cadeiras de Rodas. Revista Brasileira Ciência e Movimento, v. 21, n. 1, p. 139-150, 2013. 
ONTAÑÓN, Teresa; DUPRAT, Rodrigo; BORTOLETO, Marco Antonio. Educação Física e atividades circenses:"o estado da arte”. Movimento (ESEF/UFRGS), v. 18, n. 2, p. 149-168, 2012. Disponível em: http://www.seer.ufrgs.br/Movimento/article/view/22960/. Acesso em 5 de fev. de 2018.

PAES, Roberto Rodrigues. Educação física escolar: o esporte como conteúdo pedagógico do ensino fundamental. Canoas: Ed. Ulbra, 2001.

PASKA, V.; MIRANDA, M.; RESENDE, H. Analysis of the thematic and theoreticalmethodological trends in the scientific production on handball from the 90s on. FIEP Bulletin. v.76 (Special Edition), 103-105, 2006.

PICHETH, Fabiane Maria. PeArte: um ambiente colaborativo para a formação do pesquisador que atua no ensino superior por meio da participação em pesquisas do tipo estado da arte. 2007. 139 f. Dissertação (Mestrado em Educação) - Pontifícia Universidade Católica do Paraná, Curitiba, 2007. Disponível em: http://www.pucpr.br/biblioteca/index.php?menuid=5. Acesso em: 16 de nov. de 2016.

PINHEIRO, R. B. As representações sociais do projeto Ler e Pensar. 2012. 267 f. Dissertação (Mestrado em Educação) - Pontifícia Universidade Católica do Paraná, Curitiba, 2012. Disponível em: http://www.biblioteca.pucpr.br/tede/tde_busca/arquivo.php?codArquivo=2395. Acesso em : 11 jun. 2017.

PIRES, Daniel Alvarez. FLORES, Lucinar Jupir Forner; BRANDÃO, Maria Regina Ferreira. Situações de jogo causadoras de estresse de categorias de base de handebol: Uma abordagem crosscultural. Revista da Faculdade de Educação Física da UNICAMP, Campinas, v. 6, ed. Especial, p. 463-476, jul. 2008.

PRIETO, Jaime; GÓMEZ, Miguel Ángel; SAMPAIO, Jaime. A bibliometric review of the scientific production in handball. Cuadernos de Psicología del Deporte, 15(3), 145-154, 2015.

REIS, Heloisa Helena Baldy; CASTELLANI, Rafael Moreno. Caracterização dos cursos de handebol nas instituições de ensino superior públicas. Revista da Faculdade de Educação Física da UNICAMP, Campinas, v. 10, n. 2, p.103-120, maio/ago. 2012.

REVERDITO, Riller Silva; SCAGLIA, Alcides José; PAES. Roberto Rodrigues. Pedagogia do esporte: panorama e análise conceitual das principais abordagens. Motriz, Rio Claro, v. 15, n. 3, p. 600-610, jul.set. 2009.

RICCI, Giuliano Salera; REIS, Heloisa Helena Baldy; MENEZES, Rafael Pombo; DECHECHI, Clodoaldo José; RAMARI, Cintia. Avaliação da aprendizagem do handebol por jovens entre 11 e 14 anos a partir do método situacional. Revista Pensar a prática, Goiânia, v. 14, n. 1, p. 1-18, jan./abr. 2011.

RUFINO, Luiz Gustavo Bonatto; FERREIRA, Aline Fernanda; CARVALHO, Amarílis Oliveira; RICCI, Christiano Streb; DARIDO, Suraya Cristina. Educação Física escolar no Ensino Médio: analisando o Estado da Arte. Revista Brasielira de Ciências do Esporte, v. 36, n. 2, p. 353-369, 2014.

RUFINO, Luiz Gustavo Bonatto; DARIDO, Suraya Cristina. A produção científica em pedagogia 
do esporte: análise de alguns periódicos nacionais. Conexões, Campinas, v.9, n.2, p.110-32, 2011.

SANTOS, Petrus Gantois Massa Dias; MELO, Thamara Thais Santos; OLIVEIRA, Gledson Tavares de Amorim; CARVALHO, Paulo Roberto Cavalcanti. Somatótipo, composição corporal e capacidades físicas em atletas de voleibol e handebol. Revista Mackenzie de Educação Física e Esportes, São Paulo, v. 13, n. 2, p. 42-52, jul./dez. 2014.

SCAGLIA, Alcides José. Novas tendências em pedagogia do esporte. In: BABINO, H. F. Inteligências Múltiplas- Uma experiência em pedagogia do esporte e da atividade física no SESC São Paulo. São Paulo: Edições SESC, 2014.

SILVA, Nadia Lima; FERREIRA, Marcos Santos; PASKO, Vanessa Cerqueira; RESENDE, Helder Guerra. A prática do handebol na cultura físico-esportiva de escolares do Rio de Janeiro. Revista Movimento, Porto Alegre, v. 17, n. 4, p. 123-143, out./dez. 2011.

TELES, Nélio; VOLOSSOVITCH, Anna. Influências da variáveis contextuais no desempenho das equipes nos últimos 10 minutos do jogo de handebol. Revista Brasileira de Educação Física e Esporte, São Paulo, v. 29, n. 2, p. 177-87, abr./jun. 2015.

UEZU, Rudney; AMARAL, Renata Macário Vieira; PAES, Fernando de Oliveira; MASSA, Marcelo. Critérios para seleção de talentos esportivos no handebol masculino. Revista Mackenzie de Educação Física e Esporte, v. 7, n. 3, p. 71-78, 2008.

VASQUES, Daniel Giordani; MAFRA, Luiz Fernando; GOMES, Bruno Antonio; LOPES, Adair Da Silva. Comparação de características morfológicas por posição defensiva de jogo de atletas de handebol do Brasil. Revista Brasileira Ciência e Movimento, v. 16, n. 1, p. 13-20. 2008.

VASQUES, Daniel Giordani; MAFRA, Luiz Fernando; GOMES, Bruno Antonio; FRÓES, Marcelo Queiróz; LOPES, Adair Da Silva. Características Morfológicas por posição de jogo de atletas masculino de handebol do Brasil. Revista da Educação Física/UEM, Maringá, v. 19, n. 1, p. 4149, 1 trim. 2008.

VENTORIN, S. Encontros nacionais de didática e prática de ensino: documentos de identidade do professor. In: SILVA, A. M. M.; MACHADO, L. B.; MELO, M. M. O.; AGUIAR, M. C. C. A. (organizadores). Educação formal e não-formal, processos formativos, saberes pedagógicos: desafios para a inclusão social. Recife: ENDIPE, 2006.

WILLIAMS, A. Mark; HODGES, Nicola J. Practice, instruction and skill acquisition in soccer: Challenging tradition. Journal of Sports Sciences, v. 23, n. 6, p. 637-650, 2005.

\section{NOTAS DE AUTOR}

\section{AGRADECIMENTOS}

Não se aplica.

\section{CONTRIBUIÇÃO DE AUTORIA}

Não se aplica 
FINANCIAMENTO

Não se aplica.

CONSENTIMENTO DE USO DE IMAGEM

Não se aplica.

APROVAÇÃO DE COMITÊ DE ÉTICA EM PESQUISA

O presente estudo foi aprovado pelo Comitê de Ética em Pesquisa loca (CAAE 65549516.0.0000.5465, 22/03/2017).

\section{CONFLITO DE INTERESSES}

Os autores declaram não haver conflitos de interesse.

\section{LICENÇA DE USO}

Os autores cedem à Motrivivência - ISSN 2175-8042 os direitos exclusivos de primeira publicação, com o trabalho simultaneamente licenciado sob a Licença Creative Commons Attribution Non-Comercial ShareAlike (CC BY-NC SA) 4.0 International. Esta licença permite que terceiros remixem, adaptem e criem a partir do trabalho publicado, desde que para fins não comerciais, atribuindo o devido crédito de autoria e publicação inicial neste periódico desde que adotem a mesma licença, compartilhar igual. Os autores têm autorização para assumir contratos adicionais separadamente, para distribuição não exclusiva da versão do trabalho publicada neste periódico (ex.: publicar em repositório institucional, em site pessoal, publicar uma tradução, ou como capítulo de livro), com reconhecimento de autoria e publicação inicial neste periódico, desde que para fins não comerciais e compartilhar com a mesma licença.

\section{PUBLISHER}

Universidade Federal de Santa Catarina. Programa de Pós-Graduação em Educação Física. LaboMídia - Laboratório e Observatório da Mídia Esportiva. Publicado no Portal de Periódicos UFSC. As ideias expressadas neste artigo são de responsabilidade de seus autores, não representando, necessariamente, a opinião dos editores ou da universidade.

\section{EDITORES}

Mauricio Roberto da Silva, Giovani De Lorenzi Pires, Rogério Santos Pereira.

\section{HISTÓRICO}

Recebido em: 25 de Junho de 2019.

Aprovado em: 06 de Dezembro de 2019. 